\title{
The Photo-Instrument as a Health Care Intervention
}

\author{
J. E. Sitvast • T. A. Abma
}

Published online: 20 May 2011

(C) The Author(s) 2011. This article is published with open access at Springerlink.com

\begin{abstract}
The aim of this study is to describe how hermeneutic photography and one application of hermeneutic photography in particular, namely the photoinstrument, can be used as a health care intervention that fosters meaning (re)construction of mental illness experiences. Studies into the ways how patients construct meaning in illness narratives indicate that aesthetic expressions of experiences may play an important role in meaning making and sharing. The study is part of a larger research project devoted to understanding the photostories that result from groups of psychiatric patients using the photo-instrument. Within a focused ethnography approach we employed a qualitative design of a single case study. Text analysis of photostories was combined with observational data. Data were analyzed using hermeneutic theory. Participant observations were used for triangulation and complementarity. The interaction and collaboration between health care professionals and patients in the context of a photo group emerged as core concept that underlies the photo-instrument. The interaction triggered a reframing of meaning in the patient's illness narrative that offered new perspectives on positive identity growth. The role of visualizing meaning in images was found to lend a dynamic power to the process and triggered a dialectic between real life circumstances and imagination played out in the context of situated action. The findings suggest that a positive reframing of meaning in illness narratives is facilitated by the photoinstrument.
\end{abstract}

\footnotetext{
J. E. Sitvast ( $\bowtie)$

GGNet, Network for Mental Healthcare in the Region Oost Gelderland, Kenniscentrum, Vordenseweg 12, 7230 GC Warnsveld, The Netherlands e-mail: j.sitvast@ggnet.nl
}

\section{T. A. Abma}

Department of Medical Humanities, EMGO Institute, VU University Medical Center, Van der Boechorststraat 7, 1081 BT Amsterdam, The Netherlands e-mail: emgo@vumc.nl 
Keywords Hermeneutics - Mental health and illness - Rehabilitation - Recovery · Research · Qualitative

\section{Introduction}

Illness does not only influence a person's physical well-being and psycho-social functioning, but also affects and permeates the way how we experience ourselves [8, $13,17,24]$. Serious illness, especially chronic illness, transfers a patient into another life world with particular social roles, rules and identities [24]. How a patient feels and defines his or her identity depends on the recognition one receives in the interaction with others (e.g. [17]). In this process the patient must find answers to questions: 'Why me? What is the cause of my falling ill? How can I control the illness?' This involves coming to terms with experiences of loss, overcoming fear and anger and restoring self-confidence.

This adaptation to one's illness is done by ordering illness experiences in a personal story that accounts for the onset, continuation and exacerbation or possible recovery of illness symptoms over the course of time. Patient may use plot lines, metaphores and other rhetorical devices present in narratives to find coherence and meaning in the illness, and rework a life story in the light of illness or their recovery from illness. The moral meaning of these illness narratives consists in how patients struggle for authorship over their lifes. This struggle is symbolized in one's personal narrative [45], reflecting (in the absence of exacerbation or remission of symptoms) quiesecence and homeostasis or an enhanced sense of self-efficay and rekindled aspiration [24, 45].

The telling of a story is also an event that is situated in social interaction $[3,17]$. This applies also to the stories patients tell to health care professionals. In order to be more than a source of information useful for assessment, diagnosis and intervention, there must be a mutual knowing that acknowledges the subjectivity of stories as someone's truth at that moment [13]. In the context of professional-patient interaction an open non-judgmental exchange of information is wanted, "where meanings are attained through mutual intersubjectivity rather than hierarchical levels of understanding" $[6$, p. 72, 9, 52]. This implies listening and an honouring of the suffering.

Stories may need no change, but one can nevertheless see that change occurs as the opportunity of telling one's story often offers a critical distance that is necessary for reflection $[4,13]$. When health care professionals recognize and affirm this to their patients, then they communicate a message that their stories need not be trapped within fatality but are open to change. Through narrative interventions of this kind professionals may develop a relational narrative that focuses on dialogue $[4,15,39]$ and a co-construction of a joint narrative. The dialogue that holds a central position in a relational narrative helps restoring the agency of ill persons as capable, self-defining authors and allows for a movement toward a self with possibilities [41]. This is the emancipatory potential of relational narratives.

Narrative is a means of transforming private experiences into language and involves cognitive functions as perception and recollection. It is well known that 
mental images or pictures play an important role in verbal expression and recall from memory (e.g. [29, 38, 46]). Metaphors are the most important form of imagery. They trigger a process of creative imagination that widens the horizon of the person who uses them [35], freeing him or her from the mere facts available from the narrated event. Other notions can then enter the process of meaning making, as for instance anticipations of a willed future. Ricoeur [33] used the concept of mimesis to describe how meaning in text becomes interpreted through metaphorical transformation [44]. Mimesis is a philosophical concept from classical philosophers likeAristotles and Plato. Ricoeur interpreted it as a mental process that takes place during telling a narrative in which we reflect on lived experiences. We then go through stages of distancing our direct life experiences, reflecting on them from other angles ('widening horizons') which then leads to a reformulation of lived experiences. In this reformulation metaphors and imagery play an important role. They mediate how new meanings come about. By means of metaphors we apprehend one kind of thing in terms of another, setting the imagination free to integrate memories, anticipations and wishes into images that are charged with symbolic associations. For instance, when suffering from a chronic illness comparing our body with a motor that sometimes falters (but then can be repaired) may be helpful to invoke an image and voice a perception of realities and inequities of a life with pain that is less threatening than the idea of an unremediable illness and a body that betrays us in an unpredictable way. The imagery of a mechanical device may help the narrator to open up to a differentiation between pain and suffering, making a distinction between who we are and the inflictions that beset us (see also $[12,42])$. In this way the metaphorical transformation of meaning that we endow to our lived experiences may help us in restoring to us the idea that we are to some degree the agents of our own lives. It reduces the suffering that comes from experiencing powerlessness in the face of illness and pain. From being a patient one may become a person with a chronic illness. Having an illness needs not preclude someone to have goals, strivings and ambitions. To say 'I am' is to say 'I want, I move, I do' [34]. The notion of action is important here. When, because of illness and pain, someone becomes the patient of actions by others (vs. being an agent of one's actions), this may be felt as suffering.

Mimesis is the process we go through as narrator of stories but also as we read or hear stories. We actively assimilate stories and integrate them into our life world. The way a reader understands a story and its plot may very well differ from the intentions of the author. We read the text from our own background and apply it to our own situation.

When patients are invited to picture a private experience, either by visualization or making real pictures, and narrate what they have viewed or depicted, then sensory images become iconized with meaning [16, 48]. Through a process of association and projection images are charged with value-laden impressions, feelings, memories and anticipations. They then become the vehicle or carrier of content, just as is the case with religious icons which are invested with devotion. This finding of a carrier for sometimes diffuse sensations and impressions from lived experiences that are often difficult to verbalize is a first step toward integration into more complex meaning aggregates. Intertwining picturing and narration in therapeutic settings 
reflects the dialectic played out in the natural context of situated action. When the picturing is done with photographs that are used for eliciting narrative, then we speak of hermeneutic photography. The scope for hermeneutic enquiry in general is the way how meaning is constructed and integrated within existing knowledge. In the context of health care we focus on how patients rework sensory perceptions in lived experiences from a level of mere 'sensations' into more contemplated thoughts and insights into the experience. Symbolization plays an important role in this process, often through the use of metaphors (see above). However, besides language other forms of symbolization of lived experiences are possible, e.g. visual images (photographs).

The purpose of this article is to explore the potential of hermeneutic photography within health care.

\section{Background}

\section{Photo-Elicitation}

The use of photography as an instrument of research has a long tradition in social science. It's been used and is still used as a data collection method [2,11]. Photos are shown to respondents to elicit information on key topics. This is called photointerviewing. It is based on the principle that photographs provoke (elicit) a response: photo-elicitation [20].

More recently another form of photo-interviewing came up, namely autodriving. The photographs are taken by the interviewees themselves. The photos are then used in photo-elicitation sessions $[21,22]$. There is a shift in the role of the informant and researcher: the informant has more voice in the choice of topics that are discussed and can do so with more authority because he has made the photo and can claim exclusive expertise.

\section{Photo-Elicitation in Health Care}

As an instrument for research, photo-interviewing has also been introduced in medical and nursing disciplines [19, 32, 36, 51]. Bultemeier [7], for instance, used photography as a way to inquire into the lived experiences of women with premenstrual syndrome. Drawing inspiration from psychological tests that use ambiguous images and photos to make subjects project their own interpretation into the test material, photo-elicitation is considered by some social scientists as a hermeneutical device [19] that helps subjects to project meaning [20, 54] from deeper layers of consciousness. In health care, Frith and Harcourt [14] used hermeneutic photography to capture women's experiences of chemotherapy for breast cancer. Keller et al. [23] used a hermeneutic method with photograpy to uncover contexts relevant for assessing dietary intake and physical activity in diverse ethnic groups. Oliffe and Bottorff [28] interviewed patients with prostate cancer on the photographs they had made about the experience of having cancer. Photography has also been used as a client-controlled instrument to improve quality 
of care [37]. Although these examples of photo-interviewing focused on clients' reflections on their lived experiences, this was not done for therapeutic reasons. Photo-interviewing was in the first place a research tool; the reflection was not sought for as an instrument of improving awareness for the sake of empowerment. Photo research remained descriptive; it did not serve as a vehicle for transforming social reality.

\section{Consciousness Raising and Empowerment}

Some studies, however, do reflect a more explicit therapeutic use of photography.

These studies often engage photography in an educational sense or as a means for consciousness raising and psychotherapeutic work [1, 5, 19, 47]. As an intervention in institutional care this intervention is still relatively unknown (Riley and Manias 2003). Radley and Taylor (2003) are among the very few who used photography in a hospital setting to have patients reflect on their hospital stay.

Wang and Burris [50] provide a clear example of how photo-elicitation can be combined with the agenda of empowerment, in a collective way rather than fostering individual empowerment. Participants in their study made a set of photos depicting day-to-day routines and events. They were then asked to talk about their lives as depicted in the photos. Being grounded in real experiences, the photos triggered authentic stories. The technique was used for working with underpriviliged and marginalized groups. Wang and Burris, for instance, applied photography as a means to educate Chinese women and support social action. Using photography in this sense works two ways: it validates and empowers the subjective experiences of these groups and it is a means of communicating needs, concerns and priorities to policy makers, health officials and others. Wang and Burris stressed the importance of giving voice to people who otherwise may not be heard because they lack the power, the money or the status to make themselves heard. Therefore, they called the approach 'photovoice'.

\section{Hermeneutic Photography and the Photo-instrument}

Hermeneutic photography as a therapeutic instrument aims at facilitating persons to give meaning to their life world. Photographs enable humans to find meaning through visualizing and interpreting lived experience. Making photographs of situations in one's life may be seen to trigger a reflective process in which images become the carriers of symbolic and metaphoric associations, of which the photographer had no clear idea when taking his pictures [19]. The idea that photographs produce images of real life invites action oriented associations, that can be connected with an agenda of empowerment by focusing photographs on wishes and ambitions, as was done in the photo-instrument.

We consider the photo-instrument an applied form of hermeneutic photography. Group sessions were organized with patients who were invited to endow meaning to pictures made with a disposable camera. Nurses and occupational therapists conducting the photo groups fostered the process of elicitation among participants (see also [44]). The photo groups followed a protocol developed and tested by the 
first author in an earlier phase of the study [43]. Clients make photographs, talk about them in group meetings and exhibit their photo stories to a wider audience. The broader intention of the intervention is connecting clients with sources of individual strength, thus helping them to empower them. Reflection and dialogue are essential elements in the intervention. In the intervention the dialogue between nurse facilitators and group members is a reiterating process going on during all sessions.

The photo-instrument we applied resembles the photovoice approach of Wang and Burris. Our instrument differs, however, from photovoice in its focus on the individual process of meaning making as compared to its use for research, education, social change and public health [26].

\section{Method}

\section{Setting}

Our hermeneutic photography intervention was part of a larger research project devoted to understanding the photostories that result from groups of psychiatric patients using the photo-instrument. Settings varied from a (medium-) long stay treatment ward in a psychiatric hospital, to a daytime treatment centre, and three sheltered homes. During 2005-2009 sixteen photo groups were organized (with a total of 72 participants). The criterion for inclusion in the study was recovering from a psychiatric crisis and not being severely limited by psychiatric symptoms. Beyond this criterion participants reflected an average sample of patient population when considering age, residence status (inpatients-outpatients) and diagnosis cluster (Table 1).

\section{Design}

The overall approach of the larger research project is focused ethnography. Focused ethnography differs from the classical ethnography. Other than in classical

Table 1 Frequency, average age, sexe ratio and diagnoses according to residence status in patients included at the start of the study, $N=74$

\begin{tabular}{lccccc}
\hline Variables & $\begin{array}{l}\text { Acute and } \\
\text { short stay }\end{array}$ & $\begin{array}{l}\text { Long } \\
\text { stay }\end{array}$ & $\begin{array}{l}\text { Total } \\
\text { inpatients }\end{array}$ & Outpatients & Total \\
\hline Number & 9 & 23 & 32 & 42 & 74 \\
Average age & 35 & 45 & 42 & 42 & Av. age 40 \\
Male & 3 & 11 & 14 & 15 & 29 \\
Female & 6 & 12 & 18 & 27 & 45 \\
Main diagnosis: schizophrenia related & 6 & 12 & 18 & 12 & 30 \\
Main diagnosis: mood disturbances & 0 & 2 & 3 & 5 & 8 \\
Main diagnosis: personality problems & 2 & 0 & 2 & 4 & 6 \\
Diagnosis: other & 1 & 8 & 9 & 16 & 25 \\
Missing diagnoses & 0 & 1 & 1 & 4 & 5 \\
\hline
\end{tabular}


ethnography the location may be a treatment site (such as a clinic) rather than a place of residence. "Participants may not be connected by the same culture (in its broadest sense), but share behavioural norms and a common language emanating from experiencing a common illness. Participant observation is limited to particular events or times, and interviews are generally limited to the selected topic and surrounding event" [27]. We considered participants of the photogroup as belonging to the same group, sharing the same experiences of being a psychiatric patient and going through a phase of resocialisation or rehabilitation. In nine photogroups (in total 47 participants) the researcher (first author) participated in the group sessions and made observations that together with other data contributed to the construction of cases. Cases are constructed on the basis of the trajectory that participants passed through while participating in the photogroup. The overall study follows a multiple case design.

This detail study is an single case study providing an insight into the issue what role health care professionals can play in facilitating the process of meaning (re-) construction by patients in a mental health care setting. Focusing mainly on "what" questions, a exploratory case study was called for [53]. The case was selected based on the criterion of its learning potential; it contained rich data that demonstrate how the process of meaning making develops in an intricate and subtle interaction between the facilitator (health care professional), the participant and the context of representation.

\section{Data Collection}

We collected the photographs and photo stories as told by the patient in the selected case. These photo stories were expressed in the series of meetings of the photo group (two rounds of eight sessions of $90 \mathrm{~min}$ ). Besides collecting data from photo stories the first author did participant observations of these meetings and recorded them in field notes, whereas the care professional who facilitated the group filled out observation forms after every session. The data were considered to be a complementary dataset that gave us information on the contextuality of photo stories.

\section{Analysis}

The meaning of photographs arises in a narrative context [10]. As we assume that the function of photographs is primarily the creation and maintenance of meaning, we decided for a hermeneutic analysis. We analysed text on three levels: the intratextual level of the narrative, the interactional level that serves the communication with other people and the meta level of representation [25] where the moral issue of agency and authorship is at stake. For the interactional and meta level of representation we leaned heavily on complementary data from observations and field notes (Table 2).

In the hermeneutic analysis we looked at structural elements, of which the plotline of the narrative was seen as most important. The evaluative direction of the plot (progressive, regressive) was interpreted as indication for how the participant 
gave meaning to his suffering. Besides progressive and regressive plots we distinguished a consolidation or stability in a narrated life [18]. On the interactional level we analyzed how a story served certain relational functions. On a meta level of representation we analysed how someone presented himself as a moral agent. For all three levels we considered how the care professional who facilitated the group influenced choices that were made by the participant.

\section{Validity and Reliability}

"Cameras do not take photographs, people do", (Beyers cited in [31]). In hermeneutic photography this means that research participants make their own photographs and do their own interpretation. Photographs are always made in a certain context that partially lends them their meaning. We cannot detach this context from the interpretation. To meet demands of plausibility and believability, the researcher must therefore offer "full contextual detail" [31], meaning a detailed account of both the external and internal photo context [2]. The external context is, for instance, the micro context of the photo group. Sharing the photography experience with other people may influence the choice of photographs and the story you tell. So may the fact that you are a user of psychiatric services. The researcher must therefore have an open view to photographs that are disqualified, "silent stories" that are not voiced. He must pay attention to group dynamics and other forces that urge for conformity when participants perform as photographers and give a representation of their life world. The researcher needs to be reflexive. By giving reflexive accounts the researcher renders explicit the process by which data and findings were produced, thus creating plausibility and believability. Triangulation of methods enabled the team to cover a rich variety of perspectives.

\section{Ethical Considerations}

The study was executed in accordance with the norms and regulations under Dutch legislation on medical research (the WMO-Law) and was approved by the appropriate Medical-Ethical Board. A proper informed-consent procedure was part of the research protocol.

The patient whose case we used in this paper, was asked explicit consent for allowing us to publish his photos and his story, after informing him on the implications of his decision.

\section{Results}

Experiences From Practice: The Case of Boris

We will now illustrate how hermeneutic photography, in casu the photo-instrument, facilitates meaning (re-)construction with details from one case. Boris is a 49 year old man, vulnerable for psychotic decompensation and depression. He has been 


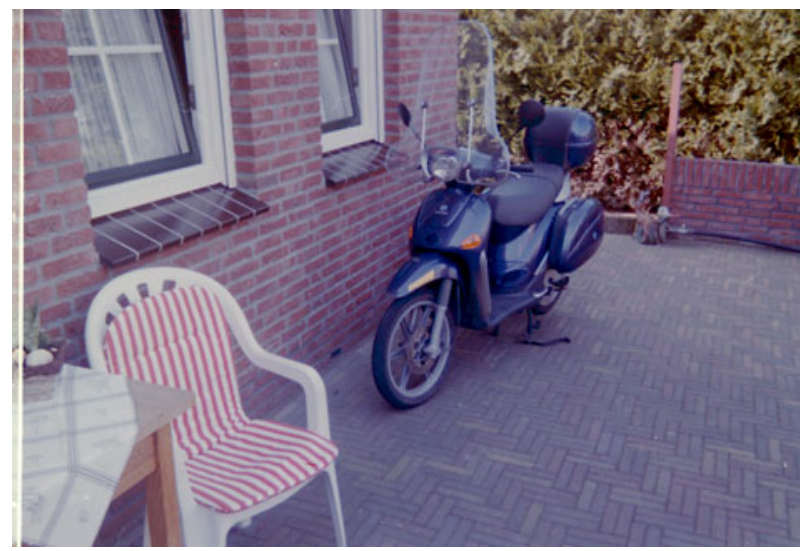

Fig. 1 The scooter

married, but his wife divorced him. He has two children who still live with his wife. He regularly visits them. At the time of his participation in the photo group, he has been living in a sheltered home for 6 months. He has had some problems with his weight, for which he consulted a dietician. In response to the photography assignment to make pictures of things and persons that were dear to him or that he valued highly, he photographed, among other things, his scooter (Fig. 1).

What did he tell about this photograph? The scooter meant for him that he could go and visit his ex-wife and his teenager children whenever he wanted. He commented on his photographs of his scooter as follows: "This is a fine picture of my scooter. It looks like a motor-cycle... It gives me a feeling of freedom and openness when I ride and feel the wind". This is a statement that conforms to cultural and social accepted ways of expressing freedom, but there is a curious twist that turns his feelings toward experiences of loss:

It is an artful machine. It runs and does not falter; it is mechanical. Me, I am not like that. I have no skills. Yes, I had at one time when making videos of weddings. I did the video-making when things were still okay with me. Shooting film all day long, that's what I liked to do and wedding couples were always contented with the result. You know, I'm also good at...smoking.

This part of his story reflected Boris' powerlessness facing the problems in his life before he moved to the sheltered home. Lacking skills for self-maintenance, he had become depressed and had slipped in self-neglect. Now he was on the road back again. There is a close interplay of reality and representation in Boris'story that called for a reflexive reading of text (Walsh, cited in [30]). This implied also checking how his mentor nurse looked upon his functioning and how she interpreted his agency. All these observations came together and were related to an analysis of how his story fitted his autobiography and was congruent with actual choices and challenges Boris was facing. 


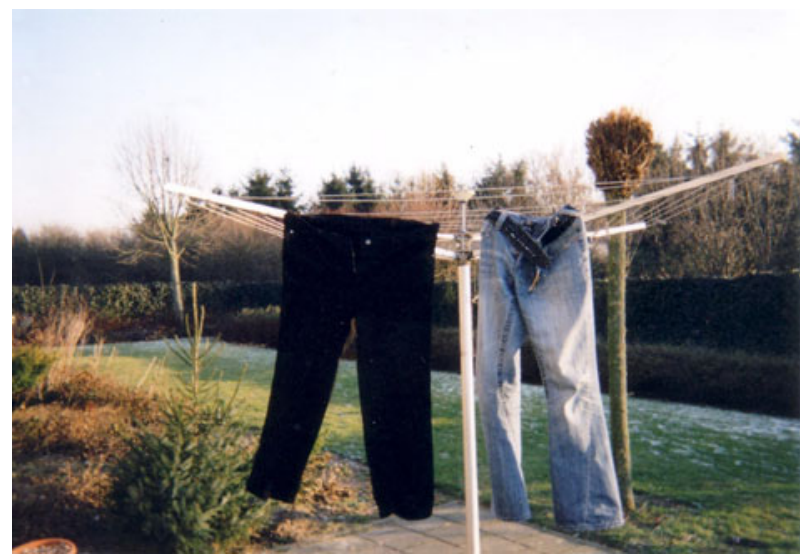

Fig. 2 Two pairs of trousers with different sizes on a drying mill: "Losing weight is important. I'm too heavy now. A better physical condition is healthy. Now I'm tired every time I do something. I think it is hard to lose weight"

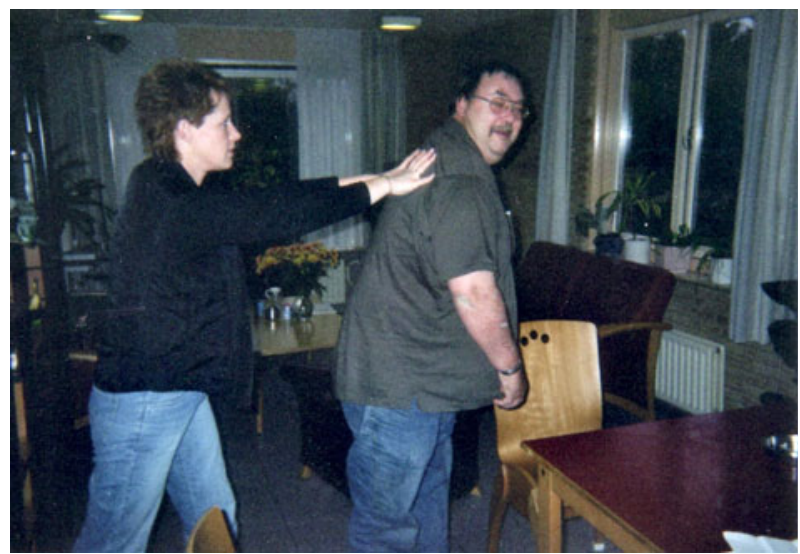

Fig. 3 Martha, the group facilitator pushing him: "I need help to lose weight. I move too little. I think it is not that easy and I am not motivated"

A first series of 8 sessions is followed up by a second one, focusing on photographing a goal or wish that participants wanted to realize. Boris selected five photographs that formed the backbone of a photo story. We will provide excerpts from his story (Figs 2, 3, 4, 5, 6).

Analysis

We analysed Boris' second series of photographs in relation to what he told us and the observations of the nurse and the researcher. The images were clearly premeditated to match his point of view: how difficult it is to lose weight, and that one is dependent on others to realize such aim. Together with what Boris told us the 


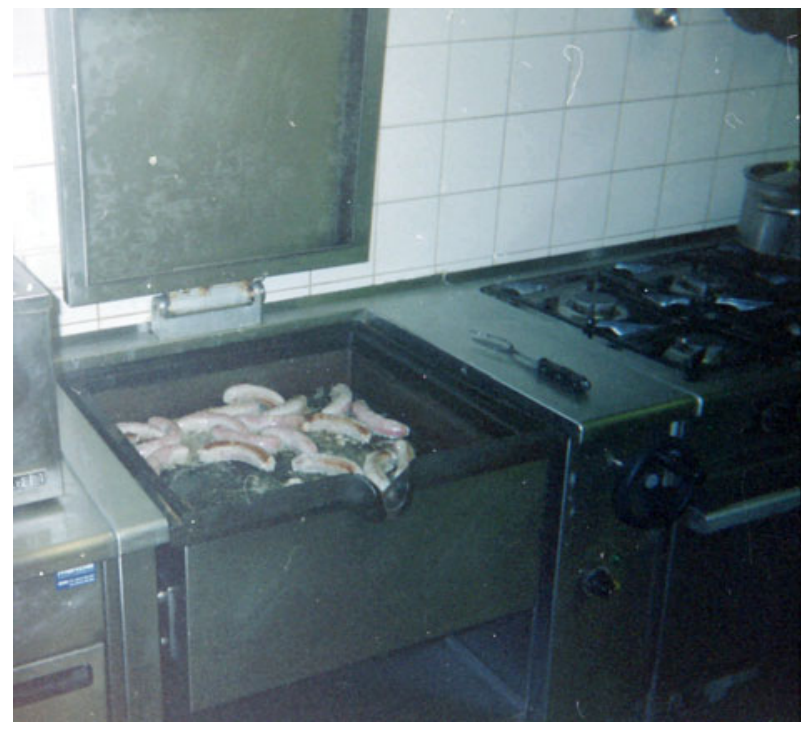

Fig. 4 Sausages on a cooking-range: "Nice sausages on the roaster. I love them, but I can't have too much of them. Actually I don't eat that much. But if I like something, I eat more. When I look at the picture I'm getting a bit peckish. The smell and the taste of the sausages (trigger me). I've been to the dietician for it. She couldn't help me. If I eat less, I keep being hungry. It affects how I feel”

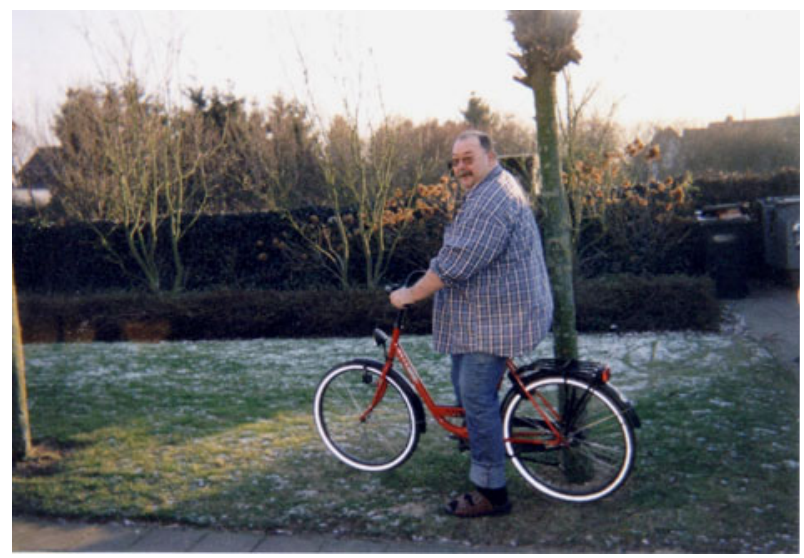

Fig. 5 Boris on a bike: "Biking would be a challenge. They tell me to go biking, but it's up to me to actually do it. If I want to lose weight then I have to. Maybe a tandem bike is a good idea. Then I don't have to bike on my own"

five pictures made a coherent story. The story had no clear perspective. There is no progressive or regressive outcome, whereas consolidation or stability is also not at stake.

A further narrative analysis however makes clear that the story serves as an excuse for Boris. It explains why it so difficult to lose weight. It does so in a lightly 


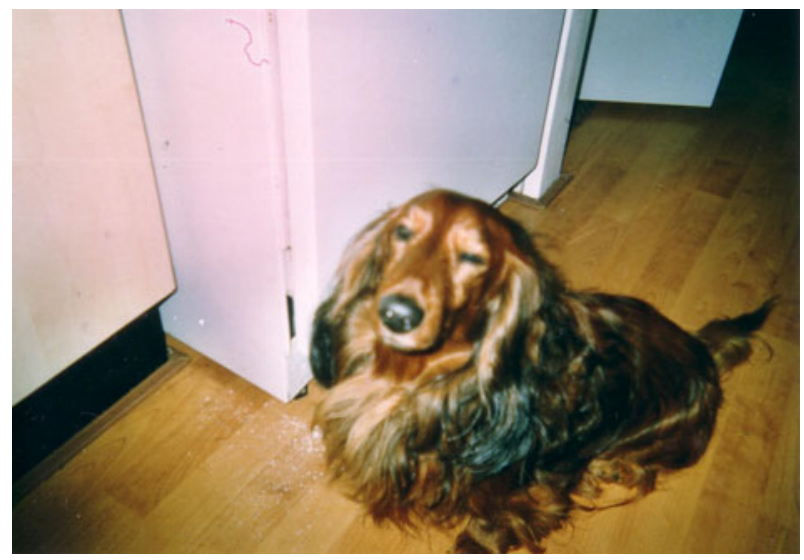

Fig. 6 Boris and his dog: "Max is my resource (referring to the assignment that instructed participants to also photograph their resources that supported them). He makes me walk much further than I otherwise would do. Max walks alongside me and together we take a break every now and then, when he wants to pee"

ironical style, that makes Boris sympathetic to us. The big-sized trousers next to the smaller sized trousers: the image has a touch of pathos to it. The point of his story seems to be: I ' $m$ so eager to lose weight, but I can't do it; I need help. At the same time the text breathes aloofness and a kind of self-consciousness. He uses the I-form: "I have been to the dietician. This didn't help me". There is no selfvictimization. Sitting on his bike he looks at us and smiles, enjoying the attention in a sphere of self-irony. There is an undertone of feeling impotent to do something about his problem, but also a strong wish not to let this feeling dominate his life too much. His pictures and texts convey this in a strong way, for instance: the image of the dachshund Max, trotting down the street on his little paws and drawing Boris along. Boris plays trumps with a skilful use of a cultural repertoire of irony.

We noted that Boris used humour as a defence mechanism against too much confrontation with his limitations, but nevertheless his texts came to show him as vulnerable and open in the course of time. From observations and what he said about this himself we recognized that Boris came to experience the group as a safe haven that helped him to let go his earlier reticence. Eventually he performed the assignment in a playful way. He enjoyed the attention from others, for instance when Martha (the care professional) gave some logistic support in the making of some photographs (as we can see in the photograph where she pushes him).

We first considered how the photographs were made. The fact that the photographs are staged and are taken within the enclosed space of the sheltered home is of importance, as well as Boris figuring himself as central subject. There is a certain self-consciousness that speaks from the images themselves. For instance, Boris sitting on a bicycle demonstrates his wish to engage in more physical activities. There are unintentional symbolical overtones where the bicycle stands for setting his life again in motion and also: taking the road, heading for change versus stagnation. The photograph of the two pairs of trousers is at first sight indexical: the 
picture denotes that losing weight means that he can put on trousers with a smaller size. The symbolism in this photograph is more implicit. In advertising people who have success in life are often portrayed as having a slim and slender figure. Images that show persons who are fat carry a connotation of indolence and being not so smart. Thus, Boris' photograph may symbolically refer to his wish to belong to the group of people with success and participate in society. This may be considered a silent story that Boris could not voice.

How did Boris present himself with his photographs and what image of himself did he bring across? Did shame or shyness refrain him from an eloquent presentation? Did he feel anxious about his photographs: sometimes people feel unsure whether their pictures are good enough in a technical sense or feel ashamed to tell a personal story. From participant observations we recognized that an earlier stage, when shooting the pictures, Boris had found it difficult to decide what to photograph and when, asked to select pictures that were most telling, he only chose the photographs about his struggle to lose weight after some hesitance. He speaks about his photographs in a laughing style as if he mocks himself. It seems as if he does not take himself too seriously. This might have to do, so we inferred from observation, with uneasiness in relating to group members or the nurse facilitator. It is also likely that talking about his body is an awkward thing for him to do. It touches on a taboo that many people (maybe men more than women) feel when the subject of their physical appearance comes up for discussion.

Boris' way of representing himself is an example of a rhetoric style in communication. The positive response from the other participants and the nurse helped Boris to maintain his integrity and put up a credible performance. Boris was acknowledged in his expertise of presenting a photographic report (reminiscent of wedding videos he used to make in an earlier phase in his life). He regained "face" as someone who could be respected for his skills. Where he voiced his dependency on others on certain occasions, his performance (his photographs more than his words) gave voice to a more resilient identity.

Boris' story matched real issues in his life. He developed his story from a station of powerlessness through self-irony into a more triumphant "I can!" He became an agent in his own right. Somewhere in this trajectory his readiness to really make a change was born. From observations by the health care professional we learned that his commitment was furthermore strengthened by the photo exhibition and the response from his family and fellow inhabitants of the sheltered home where he lived. He took up biking with his mentor nurse. 6 months later he had lost more than 20 kilos in weight. He was extremely proud of this.

How the Health Care Professional Facilitated Meaning (Re-)Constuction

\section{Co-construction}

Until now we focused on the way in which Boris expressed and presented his photo story. But how were his images and the accompanying text produced in the first place? The group facilitator knew that Boris had consulted a dietician and that he wanted to lose weight. When Boris pondered over the assignment to take 
photographs of a wish that he wanted to realize, she suggested him to take this as theme for his photo story. He agreed and set about taking photographs. After failing a first effort to make the photograph with the trousers as he had planned it, she offered him assistance. At first he declined the offer, but later he accepted her help. Boris told his story in a series of sessions, during which the group facilitator triggered him by questions and feedback to elaborate his story step by step until he felt safe to present it as an "official" text for the photo-exhibition.

Thus, Boris' photo story has been co-constructed with Martha right from the beginning. This is part of the external narrative [2] that determines the context of Boris' photo story. Photographs are not only made based on an assignment that frames their subject or theme, but also, in Boris' case, with the aid of the care professional conducting the group.

\section{Photo-elicitation}

Another element in the external narrative is the way in which meaning making depends on the interview technique that is called photo-elicitation. Photo-elicitation uses photographs to invoke comments, memory and discussion in the course of a semistructured interview [2]. By using photographs made by the respondents themselves the more formal aspects of interviewing can be avoided and the succeeding reflection on one's own photographs approaches a more intimate context that resembles a natural exchange over family snapshots. We have observed how this was the case with Boris and his fellow group members. There was an atmosphere of pleasantness and openness that helped Boris to make further steps. Photo stories are shared with others and there may be a tendency for photo stories to converge to common themes that are shared with other group members. Medication draining your energy was a theme that Boris said he recognized in someone else's story. At the same time the group context may refrain individuals from giving a too personal account. In the case of Boris he admitted that at first he did not like it to recount in detail what his problems were with losing weight, but after overcoming his reticence he was very open about it.

\section{Empowering Context}

Hermeneutic photography is an example of how visual media can aid disempowered people in gaining greater control over their lives. The assignment focused on the formulation of a wish that one would want to realize. The representation of his wish to lose weight helped Boris to anchor this in mental icons that gave him the drive to actually realize his wish. The following observations, made by the first author, shows how the care professional who facilitated the photo group engaged in a conversation about Boris' photographs and helped Boris to widen his horizon (a hermeneutic aspect):

Martha (the care professional) asks Boris to tell more about the challenge there is in for him. It appeared that the dietician had advised him to engage in physical activities more often. Boris tells that his scooter is in repair and that he has a bike on loan. "Aha", Martha says, "maybe you can bike then!" Boris' response is 
somewhat giggly and he says that it is not very likely that he will do that. "Maybe you need a little push, as you suggested on this picture?" Martha answers and she continues with: "When you dó move, what then triggers you?" Boris answers that he likes walking with his dog. "That is fun." Martha takes up the cue and asks Boris: "What is necessary to make biking also fun? Maybe if you go biking

Table 2 Core concepts of the photo-instrument operationalized into methodological steps (actions) and illustrated with examples from the case of Boris

\begin{tabular}{ll}
\hline Actions & Examples in the case of Boris \\
\hline Mimesis & \\
Photo-elicitation & The nurse asked Boris what the scooter on his photograph meant to him \\
Probing & $\begin{array}{l}\text { The nurse tries to surface deeper layers of meaning by asking what challenge } \\
\text { there is in for him when he mentions the issue of losing weight }\end{array}$ \\
Prolongued dialogue & $\begin{array}{c}\text { The nurse engages in a dialogue with Boris over his wish and how to realize it } \\
\text { that extends itself over several sessions. In this way the fluidity of narrative } \\
\text { truth and its changeablity is emphasized }\end{array}$
\end{tabular}

Re-iterant testing of text Boris got the opportunity to adjust his texts where he was asked to select photographs and text for the photo-exhibition, thus to integrate his newly developed understanding that losing weight was after all possible

Focusing of attention

The assignment to photograph a wish and also how one would realize this wish focused Boris on his issue. So did the instruction to group photographs together and paste a memosticker to every group with a label that described the group. There is a continuous process of selecting and prioritizing of photographs and text

Anchoring

Bridging of contexts

The nurse steered Boris toward concrete actions and a realistic scenario. She helped him to anchor his photo story in his actual life world

\section{Performance}

Holding and containment The dosed and structured way helped Boris to overcome his initial reticence. The nurse emphasized the need for confidentiality of everything that participants told during sessions. Discussing the impact of his photo story on invited guests of the exhibition the nurse helped Boris to feel responsible for exposing certain traits of himself and also to draw the line at a point beyond he wanted to keep things for himself

Organisation of a photo- Sharing his photo story with others at the photo-exhibition was another means exhibition of committing Boris to his agenda of changing his life style. At the same time it gave him an opportunity to present himself as an agent of his own life. We observed how his face shone at the opening night of the exhibition when he showed around his wife and children

Exchange of text in a peer The nurse stimulated listening to the stories of others and invited everyone to group respond to each other with positive feedback. Within-group comparison of stories contributed to a more realistic attuning or to a recognizing of potential obstacles, as was the case when Boris learned from others how medication may drain your energy. Discussing these issues with the group the nurse fostered more openness

Anticipation of future action

The nurse challenged Boris to break out of his fixation on disempowering feelings from the past and present. The opportunity to first imagine possible future actions and then make it visible mentalizes action schemes and works as a kind of virtual simulation 
together? Must someone ask you along?" She challenges him to go biking with her next week. Boris laughs and leaves it open whether he will do that (research field notes).

Left alone to make his own choice (without Martha entering on a dialogue with him), Boris would probably have taken other photographs or would have selected other photographs to relate to. But considering Boris' story as not merely a mental representation, but as an enacted story that is part of performed social behavior, we think that this "collaboration" is indispensable.

Empowerment can be defined as a process in which "the client or community takes control over the change process, determining both the goals of this process and the means to use" [49, p. 77]. It may seem contradictory that a professional plays such an important role in taking control by stimulating the client as Martha does, but then we must realize that the approach aims at decreasing her own control and facilitating a process of change. The professional acted here as a facilitator and a process-expert [49]. Furthermore, working with photographs can be compared with applied arts and artwork in the performing arts and just like them invites audience and participants to partake in "a conversation with myriad meanings, interpretations and points of view" [40]. 'Audience' may be identified as the client himself where (s)he becomes involved in the dynamics of being a spectator not only to the photographs of fellow participants but also to his/her own photographs. The role of the facilitator is also to engage the participants in this dialogue and exchange, as Martha obviously did. It is here that 'the discourse itself becomes the active generative process' [40].

\section{From Practice to Theory}

Reflecting on experiences from practice in the case of Boris we were able to identify the steps or actions the care professional had to take in facilitating Boris to present his story in a meaningful way. We present these steps here as operationalisations of two central concepts that we deduced from the theoretical framework that underlies hermeneutic photography: mimesis and performance [44].

Mimesis concerns the process of meaning (re-) construction and involves the content (the narrated event). Performance is the story-telling as a mode of communication (narrating event).

\section{Discussion}

The case we presented is the unique story of one human being. We cannot expect that every run of the intervention will result in similar outcomes. Generalization to population was not our aim. Presenting the case of Boris we were able to find patterns in the actions that health care professionals undertake when applying the photo-instrument. We do think that application of the steps we described make it likely that some form of positive growth in identity will occur and that this is sometimes the first onset of greater changes. Limitations of our study are that we restricted participation to patients who were stable enough to look upon their lives 
without greatly risking exacerbation of their psychiatric symptoms. Also patients with acute psychotic symptoms were not included. They lacked the communicative powers to profit from a group approach. Patients with deep depressions were found to engage in and ruminate too much over experiences of losses. They too were excluded from participation.

We think that the mixture of hermeneutic actions, group dynamic interventions and the aesthetic dimension of expression in images combines three professional agendas. With the photo-instrument health care professionals facilitate a process of meaning reconstruction that is set in an practical agenda of goal finding and generation of hope (1) The sensory impact of images in a photo story matches the life world focus of many health care professions, e.g. nursing (2) The visual representation facilitates a representation of patients as moral agents, which serves the empowerment of patients and reduction of their suffering from illness and disorders (3) These professional agendas have also been integrated in psychiatric rehabilitation and especially its recovery-oriented update of recent years. Connecting the photo-instrument with recovery-oriented support, the photo-instrument becomes a tool in the toolbox of health care professional working in mental health.

Health care professionals need no other skills to facilitate a photo-group than a certain proficiency in guiding a group and a sensitivity for how to respond to patients' narratives, entering in a dialogue and creating a relational narrative together with the patient. A certain flexibility is demanded to suspend the so-called 'reparation-reflex', that is the nurses' and other professional caretakers' inclination to diagnose a deficit and respond to someone's story from a interventionist perspective.

\section{Conclusion}

The findings suggest that a positive reframing of meaning in illness narratives is facilitated by the photo-instrument. The interaction and collaboration between the health care professional who guided the photo group and the patients was found to facilitate a narrative process that culminated in a representation of Boris of assumedly more authentic aspects of his identity. Although this was a one time performance in the context of the photo group we think that the occasion offered him a learning experience from which Boris may profit in a further process of personal growth. Grounded in the case we identified actions health care professionals need to take in order to foster reconstruction of meaning in a relational context of empowerment. These include among others the elicitation of meaning, prolonged dialogue, focussing attention, anchoring and organization of a photo exhibition.

Conflict of Interest No potential conflict of interests is disclosed by the authors.

Open Access This article is distributed under the terms of the Creative Commons Attribution Noncommercial License which permits any noncommercial use, distribution, and reproduction in any medium, provided the original author(s) and source are credited. 


\section{References}

1. Bach, H. (2007). Composing a visual narrative inquiry. In D. J. Clandinin (Ed.), Handbook of narrative inquiry (pp. 280-307). Thousand Oaks/London/New Delhi: Sage Publication.

2. Banks, M. (2007). Using visual data in qualitative research. London/New Delhi/Thousand Oaks: Sage Publications.

3. Bauman, R. (1986). Story, performance, and event. Contextual studies of oral narative. Cambridge: Cambridge University Press.

4. Benner, P. (2000). The roles of embodiment, emotion and lifeworld for rationality and agency in nursing practice. Nursing Philosophy, 1, 5-19.

5. Berman, H., Ford-Gilboe, M., Moutrey, B., \& Cekic, C. (2001). Portraits of pain and promise: A photographic study of bosnian youth. Canadian Journal of Nursing Research, 32(4), 21-41.

6. Bowers, R., \& Moore, K. N. (1997). Bakhtin, nursing narratives and dialogical consciousness. Advances in Nursing Science, 3, 70-77.

7. Bultemeier, K. (1997). Photo-disclosure: A research methodology for investigating unitary human beings. In M. Madrid (Ed.), Patterns of rogerian knowing (pp. 63-74). New York: National League for Nursing.

8. Bury, M. (1982). Chronical illness as biographical disruption. Sociology of Health \& Illness, 2, $167-182$.

9. Canales, M. (1997). Narrative interaction: Creating a space for therapeutic communication. Issues in Mental Health Nursing, 18, 477-494.

10. Cronin, O. (1998). Psychology and photographic theory. In J. Prosser (Ed.), Image-based research. A sourcebook for qualitative researchers (pp. 69-83). Oxon, UK/New York: RoutledgeFalmer.

11. Emmison, M., \& Smith, P. (2000). Researching the visual: Images, object, contexts and interactions in social and cultural enquiry. London: Sage.

12. Frank, A. W. (1995). The wounded storyteller. Body, illness, and ethics. Chicago/London: The University of Chicago Press.

13. Frank, A. W. (1998). Just listening: Narrative and deep illness. Families, Systems \& Health, 3, 197-212.

14. Frith, H., \& Harcourt, D. (2007). Using photography to capture women's experiences of chemotherapy: Reflecting on the method. Qualitative Health Research, 17(10), 1340-1350.

15. Gadow, S. (1999). Relational narrative: the postmodern turn in nursing ethics. Scholarly Inquiry for Nursing Practice, 30(1), 57-70.

16. Gaydos, H. L. (2005). Understanding personal narratives: an approach to practice. Journal of Advanced Nursing, 3, 254-259.

17. Gergen, K. J. (1994). Realities and relationships. Soundings in social construction. Cambridge, MA/ London, UK: Harvard University Press.

18. Gergen, K. J., \& Gergen, M. M. (2001). Narratives of the self. In L. P. Hinchman \& S. K. Hinchman (Eds.), Memory, identity, community. The idea of narrative in the human sciences (pp. 161-184). Albany: State University of New York Press.

19. Hagedorn, M. I. (1996). Photography: An aesthetic technique for nursing inquiry. Issues in Mental Health Nursing, 17, 517-527.

20. Harper, D. (2002). Talking about pictures: A case for photo elicitation. Visual Studies, 17(1), 13-26.

21. Heisley, D. D., \& Levy, D. J. (1991). Autodriving: A photo-elicitation technique. Journal of Consumer Research, 18, 257-272.

22. Joanou, J. P. (2009). The bad and the ugly: Ethical concerns in participatory photographic methods with children living and working on the streets of Lima, Peru. Visual Studies, 24(3), 214-223.

23. Keller, C., Fleury, J., Perez, A., Ainsworth, B., \& Vaughan, L. (2008). Using visual methods to uncover context. Qualitative Health Research, 18(3), 428-436.

24. Kleinman, A. (1988). The illness narratves. Suffering, healing and the human condition. NewYork: Basic Books.

25. van Leeuwen, T. (2001). Semiotics and iconography. In T. van Leeuwen \& C. Jewitt (Eds.), Handbook of visual analysis (pp. 92-118). Sage: London.

26. McNamara, S. (2009). Voices of recovery. Boston: Boston University Center for Psychiatric Rehabilitation.

27. Morse, J. M., \& Field, P. A. (1996). Nursing research. The application of qualitative approaches. London: Stanly Thornes (Publishers). 
28. Oliffe, J. L., \& Bottorff, J. L. (2007). Further than the eye can see?: Photo-elicitation and research with men. Qualitative Health Research, 17(6), 850-858.

29. Pavio, A. (1972). Imaginary and verbal processes. New York: Rhinehalt and Winston.

30. Pink, S. (2007). Doing visual ethnography. London/New Delhi/Thousand Oaks: Sage Publications.

31. Prosser, J., \& Schwartz, D. (1998). Photographs within the sociological research process. In J. Prosser (Ed.), Image-based research. A sourcebook for qualitative researchers (pp. 115-130). Oxon, UK/ New York: Routledge Falmer.

32. Radley, A., \& Taylor, D. (2003). Images of recovery: A photo-elicitation study on the hospital ward. Qualitative Health Research, 13, 77-99.

33. Ricoeur, P. (1981). Hermeneutics and the human sciences. Cambridge: Cambridge University Press.

34. Ricoeur, P. (1992). Oneself as another. Chicago/London: The University of Chicago Press.

35. Ricoeur, P. (2003). The rule of metaphor. The creation of meaning in language (Robert Czerny, Trans.). Oxon, UK: Routledge. (Original title: La Métaphore vive).

36. Riley, R., \& Mania, E. (2003). Snap-shots of live theatre: The use of photography to research governance in operating room nursing. Nursing Inquiry, 10, 81-90.

37. Royers, T. (2000). Beleving in beeld. Bewoners van verzorgingshuizen fotograferen hun Wereld (Title in Dutch. Translation: Images of experiences. Inhabitants of Homes of the Elderly making Photographs of their Lifeworld). Utrecht: NIZW.

38. Rubin, D. C., \& Greenberg, D. L. (2003). The role of Narrative in recollection: a view from cognitive psychology and neuropsychology. In G. Fireman, T. McVay, \& O. Flanagan (Eds.), Narrative and consciousness: literature, psychology, and the brain (pp. 53-85). New York: Oxford University Press.

39. Sakalys, J. A. (2000). The political role of illness narratives. Journal of Advanced Nursing, 6, 1469-1475.

40. Sanchez-Camus, R. (2009). The problem of application: Aesthetics in creativity and health. Health Care Analysis, 17, 345-355.

41. Sandalowski, M. (1994). We are the stories we tell: Narrative knowing in nursing practice. Journal of Holistic Nursing, 12, 23-33.

42. Scarry, E. (1985). The body in pain: The making and unmaking of the world. New York: Oxford University Press.

43. Sitvast, J. E. (2004). Fotografie als verpleegkundige interventie. Dwingeloo: Kavanah.

44. Sitvast, J. E., Abma, T. A., Lendemeijer, H. H. G. M., \& Widdershoven, G. A. M. (2008). Photo stories, ricoeur, and experiences from practice. A hermeneutic dialogue. Advances in Nursing Science, 31(3), 268-279.

45. Sitvast, J. E., Abma, T. A., \& Widdershoven, G. A. M. (2010). Façades of suffering: Clients' photo stories about mental illness. Archives of Psychiatric Nursing, 24(5), 349-361.

46. Smith, M. C., \& Magee, L. E. (1980). Tracing the time-course of picture-word processing. Journal of Experimental Psychology, 109, 373-392.

47. Spence, J. (1984). Putting myself in the picture: A political, personal and photographic autobiograhy. Seattle: The Real Comet Press.

48. Stuhlmiller, C. M., \& Thorsen, R. (1997). Narrative picturing: A new strategy for qualitative data collection. Qualitative Health Research, 7, 140-149.

49. Tengland, P.-A. (2008). Empowerment: A conceptual discussion. Health Care Analysis, 16, 77-96.

50. Wang, C., \& Burris, M. A. (1997). Photovoice: Concept, methodology, and use for participatory needs assessment. Health Education \& Behaviour, 24(3), 369-387.

51. Weiser, J. (1993). Phototherapy techniques. Exploring the secrets of personal snapshots and family albums. San Francisco: Jossey-Bass Publishers.

52. Wiltshire, J. (1995). Telling a story, writing a narrative: Terminology in health care. Nursing Inquiry, 2, 75-82.

53. Yin, R. (1994). Case study research: Design and methods (2nd ed.). Beverly Hills, CA: Sage Publishing.

54. Zaltman, G. (2003). How customers think. Essential insights into the mind of the market. Boston: Harvard Business School Press. 